\title{
Lost in the socially extended mind: Genuine intersubjectivity and disturbed self-other demarcation in schizophrenia
}

Tom Froese ${ }^{1 *}$ and Joel Krueger ${ }^{2}$

${ }^{1}$ Embodied Cognitive Science Unit, Okinawa Institute of Science and Technology Graduate University, 1919-1 Tancha, Onna, Okinawa, 904-0495, Japan

${ }^{2}$ Sociology, Philosophy, and Anthropology, University of Exeter, Amory, Rennes Drive, Exeter EX4 4RJ, UK

*Corresponding author: tom.froese@oist.jp

\begin{abstract}
Much of the characteristic symptomatology of schizophrenia can be understood as resulting from a pervasive sense of disembodiment. The body is experienced as an external machine that needs to be controlled with explicit intentional commands, which in turn leads to severe difficulties in interacting with the world in a fluid and intuitive manner. In consequence, there is a characteristic dissociality: Others become problems to be solved by intellectual effort and no longer present opportunities for spontaneous interpersonal alignment. This dissociality goes hand in hand with a progressive loss of the socially extended mind, which normally affords opportunities for co-regulation of cognitive and affective processes. However, at times people with schizophrenia report that they are confronted by the opposite of this dissociality, namely an unusual fluidity of the self-other boundary as expressed in experiences of ambiguous body boundaries, intrusions, and even merging with others. Here
\end{abstract}


the person has not lost access to the socially extended mind but has instead become lost in it, possibly due to a weakened sense of self. We argue that this neglected aspect of schizophrenic social dysfunction can be usefully approached via the concept of genuine intersubjectivity: We normally participate in a shared experience with another person by implicitly co-regulating how our interaction unfolds. This co-regulation integrates our respective experience's dynamical bases into one interpersonal process and gives the interaction an ambiguous second-person character. The upshot is that reports of abnormal self-other fluidity are not indicative of hallucinations without any basis in reality, but of a heightened sensitivity and vulnerability to processes of interpersonal alignment and mutual incorporation that form the normal basis of social life. We conclude by discussing implications of this view for both the science of consciousness as well as approaches to intervention and therapy.

\section{Introduction}

Cognitive science has traditionally approached social cognition from the perspective of methodological individualism, whereby our whole experience of social life could in principle be realized by a single brain-in-a-vat (Searle, 1990). More recently, there is a growing interest in the role of social interaction for social cognition, but often the contribution of others is still relegated to merely external or contextual factors, such as sources of information or as triggers for neural activations or cognitive processes that are ultimately realizable in individual brains (Gallotti \& Frith, 2013; Goldman \& de Vignemont, 2009; Herschbach, 2012). In other words, recognition of the importance of social interaction generally stops short of treating that interaction process itself as part of the cognitive. 
Yet in recent theoretical developments toward greater recognition of embodied, embedded, extended, and enactive approaches to cognitive science, so called "4E cognition" (Newen, de Bruin, \& Gallagher, 2018), there is also increasing acceptance of the possibility that interaction with others, in itself, is an essential part of cognitive processes (De Jaegher, Di Paolo, \& Gallagher, 2010; Di Paolo, Cuffari, \& De Jaegher, 2018; Fuchs, 2018; Gallagher, 2013; Krueger, 2013). This theoretical development has been applied to qualitative and cultural studies of intercorporeal practices (Durt, Fuchs, \& Tewes, 2017; Meyer, Streeck, \& Jordan, 2017), and is starting to be cashed out in experimental terms. There is growing evidence from a variety of fields that social cognition is fundamentally different when we are in interaction with others rather than merely observing them (Schilbach et al., 2013). For instance, some of our work on social interaction using agent-based simulation modeling (Candadai, Setzler, Izquierdo, \& Froese, 2019) and human real-time interaction paradigms (Froese, Iizuka, \& Ikegami, 2014) has demonstrated that two interacting agents can form larger, coupled systems with new properties and processes at the collective level. These results are in line with theoretical developments that imply that social interaction can give rise to cognitive processes that could not be realized by the individuals in the absence of that social coupling, such as forms of collective memory (Sutton, 2008), patterns of interpersonally distributed emotion-regulation (Varga \& Krueger, 2013), and even aspects of phenomenal consciousness (Kirchhoff \& Kiverstein, 2019).

We will refer to experience with a shared, social interactive basis as genuine intersubjectivity (Froese, 2018). This concept is loosely inspired by phenomenological research into intersubjectivity, social groups, and the 'we' (for a review of the classical authors on these topics, see Zahavi 2001), but it is formulated in the context of recent developments in $4 \mathrm{E}$ cognition. Specifically, genuine intersubjectivity refers to a subset of the phenomena captured by the notion of the socially extended mind (Krueger, 2011; 2013), 
namely that subset which has to do with the socially extended lived experience that is associated with the co-regulated real-time interaction taking place between two or more persons. The concept therefore explicitly pursues a middle way between two radical positions: On the one hand, by being tied to concrete social encounters, the notion of genuine intersubjectivity can be distinguished from transcendental interpretations of intersubjectivity, like the phenomenological concept of open intersubjectivity, which refer to the a priori constitutive impact of other subjects regardless of their actual presence (e.g. Varga, 2013). On the other hand, the qualifier "genuine" is also intended to highlight that this concept contrasts with the prevalent theories of social cognition in cognitive science that categorically reject any constitutive role of others for a person's social cognition, even during concrete social interaction (e.g. Gallotti \& Frith, 2013). In other words, the concept usefully accepts a broader constitutive basis of lived experience than traditional cognitive science, and yet not as broad as the constitutive basis assumed by transcendental intersubjectivity.

Genuine intersubjectivity is nothing mysterious; it simply means that social interaction makes a difference to lived experience: how we relate to the world in each moment of our experience is not independent from how we interact with others in that moment. For instance, think of two people engaged in a spontaneous dance: The fluid and tightly coordinated movements would be impossible to make in isolation, that is, without the mutually responsive co-regulation of the unfolding embodied interaction. Moreover, it is precisely this shared participation in the dance that transforms the experience into something that "we" do together. Thus, by making genuine intersubjectivity the starting point of our investigation into social cognition, it arguably brings the science of social cognition much closer to our normal experience of the embodied and interactive basis of social life, especially when compared to traditional, supposedly "folk" psychological approaches (Ratcliffe, 2007). 
This premise also helps us to make better sense of the disorders of social cognition. Traditional approaches tend to over-narrowly look for the causes of these disorders in the cognitive malfunctioning of detached social observation, such as theory of mind or mental simulation (Gerrans \& McGeer, 2003). However, paradoxically, people on the schizophrenic spectrum often intentionally employ sophisticated mindreading strategies and in a pervasive manner, yet without being able to properly compensate for the lack of commonsense social understanding (Froese, Stanghellini, \& Bertelli, 2013). Genuine intersubjectivity helps us to rethink this social dysfunction as resulting instead from disordered embodied interaction, as already highlighted in the field of phenomenological psychopathology (Fuchs, 2005; Stanghellini, 2004). When the body is no longer implicitly lived through, it awkwardly stands out in experience almost like an object or machine to be explicitly controlled (de Haan \& Fuchs, 2010). Accordingly, the function of embodied interaction to disclose the world to perceptual experience becomes impaired and there is a progressive loss of the scaffolding provided by the socially extended mind, which also has disruptive consequences for social perception and social cognition (Krueger \& Aiken, 2016), affect regulation (Krueger, in press-b), and eventually for thought (Ratcliffe, 2017a).

However, at times people with schizophrenia report that they experience the opposite of dissociality, namely an unusual fluidity of the self-other boundary as expressed in unpleasant experiences of ambiguous body boundaries, intrusions, and even merging with others (Lysaker, Johannesen, \& Lysaker, 2005). Here the person has not lost access to the socially extended mind, but has instead become lost in it, possibly due to a weakened sense of self. This anomaly was only briefly summarized in the Examination of Anomalous SelfExperience (EASE) under the heading "4.1 Confusion with the Other" (Parnas et al., 2005): The patient experiences himself and his interlocutor as if being mixed up or interpenetrated, in the sense that he loses his sense of whose thoughts, feelings, or 
expressions originate in whom. He may describe it as a feeling of being invaded, intruded upon in a nonspecific but unpleasant or anxiety-provoking way. (Parnas et al., 2005, p. 254)

Recently, this neglected anomaly received a more elaborate treatment in the Examination of Anomalous World Experience (EAWE) as part of Domain 3 "Other Persons" (Sass et al., 2017), specifically under heading “3.7 Disturbance of Self-Other Demarcation”.

The subject feels that the basic sense of independence or separateness of self and other persons has broken down or become much more fluid than normal. This may involve feelings of unusual empathy, openness, control, fusion, or confusion between self and others-whether experienced physically, psychologically, or concerning identity. (Sass et al., 2017, p. 28)

Despite the growing interest in analyzing the intersubjective dimension of schizophrenia (e.g., Fuchs 2015; Henriksen \& Nilsson, 2017; Van Duppen 2017), this disturbance of selfother demarcation has so far received little attention.

We argue that this neglected aspect of the social dimension of schizophrenia can also be usefully approached via the concept of genuine intersubjectivity: We normally participate in a shared experience with another person by implicitly co-regulating how our interaction unfolds (Froese, 2018). This integrates our respective experience's dynamical bases into an extended body and gives the interaction an ambiguous second-person character (Froese \& Fuchs, 2012; Fuchs \& De Jaegher, 2009). The upshot is that reports of abnormal self-other fluidity are not indicative of hallucinations without any basis in reality, but of a heightened sensitivity and vulnerability to processes of interpersonal alignment and mutual incorporation that form the normal basis of social life. Like in the case of other symptoms of schizophrenia, it is arguably such a fundamental alteration of self-awareness that is at the core of later developing delusions (Fuchs, 2013). 
We conclude by discussing implications of this view for both approaches to intervention and therapy as well as the science of consciousness more generally. Specifically, we consider how body-focused therapeutic strategies such as yoga, music, and dance/movement therapies may help individuals develop the skills and sensitivities needed to more comfortably negotiate everyday processes of interpersonal alignment and mutual incorporation. We also show how disturbances of genuine intersubjectivity and the socially extended mind in schizophrenia challenge some prominent individualistic assumptions about the developmental origins of self-consciousness and about the phenomenology of the minimal self.

\section{The Socially Extended Mind}

The idea that the basis of cognition can extend outside the head and into interactions with other people has gained increased acceptance as part of the ongoing conceptual developments of embodied, embedded, extended, and enactive cognition (e.g., Gallagher, 2013; Krueger, 2011; Sutton et al., 2010). However, whether the same is true of consciousness remains a much more contentious topic (Clark, 2009). And yet, genuine intersubjectivity is not a mysterious or elusive phenomenon.

Examples are already present from birth. Infants are born with a limited ability to selfregulate their attention, emotion, and behavior. Accordingly, they are deeply dependent upon the ongoing input of caregivers to physically "scaffold" their limited endogenous capacities and help them realize forms of self-regulation they could not realize in the absence of this social coupling. In this context, the notion of "scaffolding" refers to environmental (i.e., social and material) resources that drive and regulate human cognitive capacities.

To see an early instance of social scaffolding in action, consider breastfeeding, arguably the infant's first complex form of social interaction. Within breastfeeding episodes, 
mother and infant form a coupled social system via the rhythmic cycles and back-and-forth interplay of short feeding bursts. Via touch and gentle movements, mothers provide physical scaffolding (e.g., cradling the infant; gently "jiggling" them as a prompt to resume feeding) that organizes the infant's attention and guides their responsive behavior. However, this is not just a one-way process. Rather, mothers are, in turn, responsive to their infants: They adapt to the bout-pause rhythms of the infants sucking behavior, which allows the infant to play a participatory role in structuring the dynamics of this exchange and, in so doing, realize feats of attention and emotion-regulation that would otherwise elude them (Alberts, Kalverboer, \& Hopkins, 1983; Kaye, 1982).

As children grow and develop, they remain deeply dependent upon the scaffolding provided by the ongoing input of caregivers - primarily comprised of direct bodily contact and vocal exchanges - to extend their self-regulative abilities. There is ample developmental evidence indicating that, beyond the expressive cues distinctive of breastfeeding, caregivers use a range of different strategies to regulate infant attention-e.g., smiling, vocalizations, singing, caressing, diverting attention away from objects of distress - and, within these exchanges, infants and caregivers tightly integrate their expressive displays and realize attentional and affective convergence (Krueger, 2013; Taipale, 2016). When the infant becomes distressed by some object or event, for instance, caregivers will redirect their attention and down-regulate their emotional disturbance by singing a soothing lullaby; likewise, when they become fussy or overly-intrusive in adult contexts, sharp vocalizations and gestural manipulations from caregivers (e.g., emphatic hand-waving, leaning in to crowd the infant's visual field) function as external mechanisms that guide and control the infant's experience (Spurrett \& Cowley, 2004).

The key point is that within these early instances of genuine intersubjectivity, new cognitive processes and forms of self-regulative control emerge that would not otherwise 
exist outside of this coupled system. When part of a socially extended mind, infants can temporarily realize qualitatively new forms of attentional focusing, affective stability, and behavioral organization that exceeds their current phase of development (Tronick, 2005). Moreover, these exchanges enable infants to learn not simply from others but also through them, that is, to broaden their cognitive horizons as they begin to explore the external world (Tomasello, 1999). To be involved with others in instances of genuine intersubjectivity-even in its earliest forms-is to identity affectively with others. This is a shared process that “assimilates another person's bodily anchored psychological stance ..., in such a way that the stance becomes a potential way of the observer relating to the world from his or her own position" (Hobson \& Hobson, 2007, p. 411). The horizon-expanding character is a central epistemic function of genuine intersubjectivity.

Of course, instances of genuine intersubjectivity within socially extended minds are not confined to early infancy. They continue to develop and take shape throughout our lives. This is because the people we interact with, and the contexts in which we interact with them, provide rich forms of social and material scaffolding that drive and regulate our cognitive practices and patterns of interpersonal engagement. This scaffolding works at both local dyadic levels as well as at more encompassing group-level dynamics.

Within dyadic interactions, the gestures, facial expressions, intonation patterns, postural adjustments, and movements of others function as kinds of social scaffolding. That is, these expressive actions directly regulate the development and character of our own bodily responses. If someone smiles at us and makes a friendly gesture, for instance, these expressive actions will elicit similar responses from us and motivate an array of further friendly expressions; conversely, aggressive movements or threatening gestures compel us to tense up and prepare for our own aggressive response. Within the dynamics of face-to-face interaction, individuals spontaneously mimic others' facial expressions, gestures, and 
intonation patterns; they also coordinate and synchronize speech rhythms and bodily movements, which leads to affective convergence and heightened feelings of rapport (Bernieri \& Rosenthal, 1991; Wiltermuth \& Heath, 2009).

This socially distributed feedback loop regulates the affective dynamics of grouplevel engagements, too. When we are drawn into the exuberance of a lively party, for example, or swept along by the collective rage of a political protest or the euphoria of a live concert with thousands of other enthusiastic listeners, the expressions of others literally take hold of our bodily responses. They pull responsive movements and affective responses out of us that diachronically integrate with those of the crowd (Chartrand \& Bargh, 1999; Slaby, 2014). As with the coupling processes that characterize our dyadic engagements, these grouplevel processes create "a circular interplay of expressions and reactions running in split seconds and constantly modifying each partner's bodily state, in a process that becomes highly autonomous and is not directly controlled by the partners" (Froese \& Fuchs, 2012, p. 213). In other words, we are drawn into socially distributed co-regulatory systems that are partially comprised of scaffolding beyond our individual head. The ability to become active participants within such systems is crucial for prosocial behavior and shared experience. In addition to providing important resources for regulating our own affective experiences, socially distributed feedback loops enhance feelings of rapport, connectedness, and cooperation with others (Lakin \& Chartrand, 2003; Van Baaren, Holland, Kawakami, \& Van Knippenberg, 2004). These shared feelings are what drive instances of genuine intersubjectivity. They are at the core of our ability to perceive and respond to affordances found in others and social contexts more generally, coordinate joint actions, and remain sensitive to the often unspoken "rules of the game" (e.g., what to say, how to act, how to express and manage emotions, etc.) governing the social contexts we negotiate on a day-today basis. As we will see in more detail below, the ability to enter into socially extended 
systems such as these is compromised in schizophrenia, leading to breakdowns and disruptions of social cognition.

\section{Loss of the Socially Extended Mind}

Within phenomenological psychopathology, much recent work has focused on qualitative transformations of experience that appear to be distinctive of schizophrenia. In particular, many of these approaches argue that qualitative transformations in schizophrenia are rooted in a disturbance of the minimal or core sense of self (Parnas \& Henriksen, 2016; Sass \& Parnas, 2003).

According to these "ipseity-disturbance models"-ipseity is Latin for "self" or "itself" - this core self is a pre-reflective form of self-awareness: the enduring feeling of being a subject of experience from one moment to the next. From this perspective, all experiences-e.g., visually savoring a particularly colorful sunset; feeling a twinge of pain in your lower back; being gripped by a bout of melancholy; smiling at the memory of your deceased grandmother-occur in a first-personal mode of presentation. This first-person dimension marks that experience as belonging to a subject (i.e., the subject or owner of that experience); it is a necessary structural feature of experience that is inextricable from "the distinct manner, or how, of experiencing" (Zahavi, 2014, p. 22).

According to ipseity disturbance approaches, there is evidence that this first-person dimension can become disturbed in schizophrenia, particularly during the prodromal phase. Such disturbances are indicated by patient reports in which individuals say that they have somehow lost a felt sense of connection or immediacy with respect to their own experience. They say things like, "My I-feeling is diminished"; "My I is disappearing for me" (Parnas \& Handest, 2003, p. 125); "I am disconnected, disintegrated, diminished ... I feel that my real self has left me" (Kean, 2009, p. 1034). This self-splitting in schizophrenic self-experience 
can be understood as a pathological exaggeration of the alterity that is normally implicit in the structure of subjectivity, and which thereby reveals a "vulnerability in the functioning of auto-affection, which normally assures the feeling of self-coincidence in the constant differentiation and reintegration of the subject" (Stephensen \& Parnas, 2018, p. 639). Often, this "diminished self-affection," as it is sometimes called, is framed primarily as a disturbance of phenomenal self-consciousness. However, it is becoming increasingly recognized that self-disturbances in schizophrenia frequently harbor a pronounced bodily and social dimension as well. We will return to a deeper consideration of the social dimension of experience toward the end of this chapter, and will now focus on the bodily dimension.

Many of the negative symptoms of schizophrenia can be usefully approached as symptoms of specific kind of disembodiment (Fuchs, 2005; Stanghellini, 2004). Reports from individuals with schizophrenia spectrum disorders indicate that they often experience their bodies more like deanimated objects.

Many of these reports indicate a diminishment or loss of bodily self-intimacy, which is often a consequence of depersonalization. Instead of living transparently through their body as a unified center of agency and experience-that is, the body-assubject—-they describe feeling disconnected or alienated from their bodies. (Krueger \&Aiken, 2016, p. 131)

This kind of disembodiment—which involves a kind of hyperreflective self-monitoring (Fuchs, 2010)—not only makes it difficult to act spontaneously and flexibly in the world, it also has negative consequences for the capacity to feel related to others and to access shared meaning (Sass, 2017). Within this hyperreflective stance, habitual styles of thinking, moving, acting, perceiving, speaking, expressing emotions, and interacting with the world come to the foreground and become objects of intense scrutiny. Some patients report that thinking becomes difficult because thoughts develop spatial or object-like qualities (Parnas \& 
Handset, 2003). Others say that performing normally spontaneous actions like gesturing, falling asleep, putting a book on a shelf, or brushing their teeth becomes very difficult or even impossible due to the individuals' excessive attention to every aspect of the performance (Fuchs, 2010). This disruption is also manifest in how individuals bodily engage with the social world. Making small talk, gesturing naturally while speaking, laughing at appropriate moments in the flow of conversation, or simply knowing when and how to enter into spontaneous social exchanges with others becomes difficult due to this experience of disembodiment. The experience of disembodiment in this way leads to a kind of "attunement crisis": an inability "to attune with the current situation, to intuitively get a grasp on the thinking of the person you are talking to, and above all their emotional plane, to match it" (Stanghellini, 2004, p. 22).

The disruption of embodiment and of social cognition are thus closely related. Faced with a progressive loss of intuitive, common-sense understanding of social life, and a diminished capacity for direct social perception of others' intentions, individuals are forced to increasingly relying on detached observation and theorizing, but without being able to fully compensate for the lack of self-evidence (Froese et al., 2013). Individuals who feel disembodied, and hence end up disembedded from the social world, also have difficulties in taking advantage of the cognitive scaffolding that is normally afforded by interacting with others, i.e., when becoming entrained into a socially extended mind (Krueger, in press-b). Alongside the disaffection from one's own body and the estrangement from others, there develop more fundamental cognitive disruptions as the integrity of human experience is consistently undermined, ultimately giving rise to positive symptoms such as auditory verbal hallucinations and thought insertion (Ratcliffe, 2017a).

\section{Lost in the Socially Extended Mind}


The concept of genuine intersubjectivity allows us to appreciate how interacting with others makes a difference to our cognitive capacities, empowering us to do things we could not do on our own. And it also helps us to make sense of how a breakdown of the capacity for fluid embodied interaction can give rise to disruptions in social cognition, and even undermine the integrity of the intentional structure of consciousness, giving rise to hallucinations. But there is another characteristic anomaly often found in reports of individuals with schizophrenia spectrum disorder that has so far received less attention, namely confusions of self and other, which can also be illuminated by the concept of genuine intersubjectivity.

From the perspective of traditional cognitive science, according to which the self is inside the head and hence fundamentally separated from others, this disturbance of self-other demarcation must logically be approached as a category of positive symptoms, i.e., as hallucinations without basis in reality. However, the concept of genuine intersubjectivity provides an alternative perspective because it follows the enactive approach in accepting that a certain amount of self-other fluidity is a normal part of the human condition. For instance, the concept of participatory sense-making highlights that people's sense-making processes can become intertwined while they engage in interaction (De Jaegher \& Di Paolo, 2007), and this typically involves dynamical processes of mutual incorporation leading to what might be called an extended body (Froese \& Fuchs, 2012; Fuchs \& De Jaegher, 2009). The presence of others can move us both physically and affectively; we are moved by movement and moved to move in a reciprocal manner (Fuchs \& Koch, 2014). And yet despite this irreducible ambiguity between self and other during social interaction, we normally do not worry about who is ultimately responsible for our cognitive processes, and we do not feel that our bodies are invaded by or merged into others' bodies. If so, then what goes wrong with this kind of genuine intersubjectivity for people on the schizophrenic disorder spectrum? 
The key here is to note that the disturbance has to do with feelings of "unusual" selfother fluidity. We can get a better sense of the different forms of this disturbance by considering the items listed under EAWE heading 3.7:

3.7.1 Hyperattunement

3.7.2 Unusual Influence over Others

3.7.3 Pathological Openness

3.7.4 Experiences of Being Controlled

3.7.5 Merging or Fluid Psychological Boundaries

3.7.6 Universal Merging with Others

3.7.7 Uncertain Personal Identity/Attitudes

3.7.8 Uncertain Physical Boundaries

3.7.9 Experience of Being Imitated

What is immediately striking is that this list of items reads almost like the direct opposite of the dissociality caused by schizophrenic disembodiment we discussed in the previous section. This suggests that we might need a broader view of anomalous social experience that is associated with the schizophrenia spectrum. However, in the ancillary article to EAWE Domain 3 only a couple of items listed under heading 3.7 are mentioned, and without any attempt at conceptually integrating them with the other characteristic disruptions of this domain (Stanghellini, Ballerini, \& Mancini, 2017). Most of the discussion of the specific anomalies of this domain continues to be focused on forms of dissociality, a concept which builds on and extends the concept of autism. There is therefore an unresolved tension in current accounts of the social dimension of schizophrenia. 
The concept of genuine intersubjectivity provides us with an intuitive way of understanding this two-sided nature of social dysfunction in schizophrenia. We normally form coupled systems during social interaction, in which the interactors become integrated into a larger, collective process that shapes their individual cognitive capacities, including their social cognitive capacities. Simply put, skillful embodied social interaction facilitates direct social perception (Krueger, 2012, in press-a; McGann \& De Jaegher, 2009), so schizophrenic disembodiment will impair this direct access and thus feed into the characteristic symptoms of dissociality. But if the individual is not strongly rooted in their body, this weakened ego-pole could also create a vulnerability to the intermingling and entraining effects of social coupling. Cases of genuine intersubjectivity would then no longer present themselves as opportunities for taking advantage of the new affordances unleashed by the socially extended mind, but as a danger of becoming lost in the ensuing coupled social system. Accordingly, from our perspective the disturbance of self-other demarcation is no longer seen as a type of hallucination, but rather as rooted in an ambiguity that is part of the normal human condition:

For phenomenologists, the fluid oscillation between the body-as-subject and the bodyas-object highlights a "bodily ambiguity" at the heart of our embodied experience: as embodied subjects, we are neither wholly subjects nor wholly objects, but somehow always both. (Krueger \& Henriksen, 2016, p. 263)

The role of an unusually fluid or unstable sense of self-presence, self-intimacy, or ipseity in giving rise to schizophrenic dissociality has already been recognized (Krueger \& Henriksen, 2016; Stephensen \& Parnas, 2018), and what remains to be explored is the other side of the bodily ambiguity, i.e. when the lived distance between the self and the body becomes too attenuated. Indeed, it has been observed that some patients not only report a progressive loss of their sense of embodiment, but also problems of getting lost in their embodiment to the 
extent that they become completely absorbed in manual activities such that they can no longer maintain a sense of self at all (de Haan \& Fuchs, 2010).

Everything I do, I do with logic and reconsideration. Almost nothing works naturally, of its own accord ... However, I can also do things without even noticing. I get up, I brush my teeth, I get back, and I cannot even remember what I have done in between. That also happens. It is a combination of both: either complete automatism, or complete control. (de Haan \& Fuchs, 2010, p. 330)

Putting these different strands together, we arrive at a more general concept of affective instability that includes both hypo- and hyper-familiarity: Most frequently the affective pendulum swings toward an extreme disaffection from the body and from others, leading to hyperreflectivity, but occasionally the pendulum swings the other way toward an extreme identification with one's body and with others, leading to what de Haan and Fuchs termed "hyperautomaticity" (2010, p. 330). We suggest that in the latter case, persons on the schizophrenia disorder spectrum come to closely coincide with the alterity that is intrinsic to subjectivity (Zahavi, 1999), thereby losing (or at least weakening) the self-distance that is required for adopting a distinct first-person perspective on the world. The result is that they are uncomfortably "open" to the world, and thereby also unusually sensitive to the spontaneously entraining effects of the presence of others. Absorbed by the self-organized actions of their own objective bodies, they are vulnerable to becoming completely lost in the interactively extended body, too (Gozé, Grohmann, Naudin, \& Cermolacce, 2017). The person with schizophrenia is unable to maintain the existential balance between independence (distinction) and openness (participation), and temporary collapses into the latter side lead to "a loss of boundaries and an experienced immersion with others" (Kyselo, 2016, p. 612).

It is an open question how being lost in the socially extended mind manifests itself from the point of view of others, or how it could be measured during social interactions. One 
possibility is that the lost individual becomes abnormally entrained with the others' movements, which should be reflected in significantly increased nonverbal interpersonal synchrony. Nevertheless, the experimental consensus is that there is a notable decrease in motion synchrony, at least in individuals who are stabilized and who are typically medicated (Galbusera, Finn, \& Fuchs, 2018; Kupper, Ramseyer, Hoffmann, \& Tschacher, 2015). It would be interesting to investigate whether there is abnormal interpersonal synchrony at the level of brain and physiological activity. Alternatively, it may be the case that the lost individual's sense of self is already sufficiently weakened that even normal levels of entrainment feel too confusing, intrusive, and threatening. In this case, becoming lost in selfother confusion may instead express itself as a withdrawal from social interaction in the attempt to preserve a sense of self. This interpretation is consistent with a number of studies showing that patients in social interaction display fewer nonverbal behaviors inviting further interaction from their counterparts (Lavelle, Healey, \& McCabe, 2014).

Accordingly, what has been described as dissociality may actually encompass two distinct phenomena. On the one hand, there is an involuntary impairment of fluid social interaction capabilities arising from hypo-permeable self-other boundaries, and on the other hand there is voluntary avoidance of fluid social interaction in response to hyper-permeable self-other boundaries (Van Duppen, 2017, p. 408). We can also easily imagine that the latter compensatory strategy, while permitting the individual to confront the social world on their own terms for some time, in the long-term ultimately feeds into the former phenomenon, i.e., a degradation of social skills that becomes the basis of their more characteristic involuntary social decoupling.

If this interpretation is on the right track, then it could also help to make sense of the otherwise seemingly paradoxical finding that, whereas patients comparatively gesture less when speaking, when they do gesture more this is associated with others experiencing poorer 
patient rapport (Lavelle, Healey, \& McCabe, 2013). For while one strategy to avoid becoming lost in self-other interaction is complete social withdrawal, another, less drastic response is to continue engaging socially, but to do so in a desynchronized manner that counteracts the spontaneous tendencies for mutual entrainment that would otherwise threaten to overwhelm the weakened sense of self. From the interlocutor's perspective this alternative compensatory strategy would result in the strange experience of interacting with a person and yet their presence simultaneously hides, withdraws, and undermines itself. Accordingly, this perspective could support the development of an enactive explanation of the sense of unease or "praecox-feeling" felt by the interviewer when diagnosing patients (Varga, 2013).

Finally, this perspective also sheds new light on findings that individuals with schizophrenia exhibit normal levels of interpersonal synchrony and imitation when confronted by virtual agents or videos of others (Raffard et al., 2018; Simonsen et al., 2019). These virtual situations permit "social" interactions that do not actually involve other people, and hence there is in principle no possibility for genuine intersubjectivity nor for its characteristic self-other ambiguities. The upshot is that even if such experimental paradigms are ecologically more valid than completely passive paradigms that lack any possibility for interaction, such as viewing photos of emotional expressions, we should still be careful to generalize from artificial interactive scenarios to those involving genuine intersubjectivity.

\section{Conclusions and Further Implications}

The hypothesis of the socially extended mind has been usefully applied to make sense of schizophrenic dissociality as arising from the condition's characteristic sense of disembodiment, and the challenge of interacting with others in the fluid manner required for effective social coupling. Consequently, the condition also involves reduced access to the various forms of scaffolding normally provided by the socially extended mind. Here we have 
applied this hypothesis to a neglected aspect of the condition, namely the disturbance of selfother demarcation. We have argued that the concept of genuine intersubjectivity, i.e., that interaction with others makes a difference to individual experience in its own right, enables us to sharpen our understanding of this disturbance. It turns out that it is not the self-other ambiguity as such that is the problem, given that this ambiguity is a normal part of social interaction, but rather that there is a heightened sensitivity or vulnerability to this ambiguity. It is no longer a transparent or implicit aspect of social experience and hence can be felt as threatening and overwhelming.

There are implications for therapy: If a patient reports being disturbed by a felt ambiguity regarding self-other boundaries, a traditional internalist approach would tend to discount the disturbing experience as a delusion or hallucination without basis in reality and would try to find ways of eliminating it. Alternatively, from the perspective we have been developing here, this unusual experience is reconceived as a heightened sensitivity and vulnerability to a self-other ambiguity that is a normal, albeit usually transparently lived through, aspect of social interaction. In other words, while it agrees that it is desirable to develop ways of helping patients avoid getting lost in the socially extended mind, it also suggests that the aim should not be to eliminate experience of self-other ambiguity altogether. Given the essential role assigned to this ambiguity in the constitution of genuine intersubjectivity, interventions that completely suppress it could inadvertently contribute to symptoms of dissociality. A better approach would be to find ways of helping patients to cope and live with the self-other ambiguity that is at the core of human embodiment and intersubjectivity (Kyselo, 2016).

While they are not yet mainstream, there are nevertheless existing therapeutic approaches that may help individuals to develop the bodily, perceptual, and affective skills needed to negotiate aspects of self-other ambiguities that constitute genuine intersubjectivity. 
For example, Maiese (2015) convincingly argues for the need to develop and further explore "bottom up treatment methods," as she terms them. Such bottom-up methods include yoga, music, and dance/movement therapies. These methods may be particularly effective in the context of schizophrenia because they directly address the dynamics of bodily movement, affective expression, and interpersonal coordination and entrainment. Specifically, these are body-focused therapeutic strategies that can help individuals deepen their felt sense of bodily ownership and agency, feel more at home and engaged with their social and material environment, and develop more effective and refined ways of expressing, sharing, and regulating their emotions both alone and with others (see Galbusera et al., 2018).

For example, musical activities like listening, singing, and joint music-making provide regulative contexts in which individuals can enhance social skills like eye contact, joint attention, mimicry, and turn-taking (this is why music therapy can also be effective for children and adults with autism [Srinivasan \& Bhat, 2013]). These activities furnish rich, multimodal environments for individuals with schizophrenia to strengthen their ability to perceive fine-grained social cues in others and develop their capacity for "body-reading." In musical contexts, subjects rely on bodily expressions to communicate with one another-but expressive movements, eye contact, and mimicry tend to be more exaggerated than in nonmusical interactions, which creates more opportunities for subjects to develop their perceptual sensitivity to these things.

Additionally, musical environments provide opportunities to become experientially acquainted with what it feels like to negotiate fluctuations of agency, control, and self-other ambiguities within genuine intersubjectivity. This is because musically generated auditory and rhythmic signals scaffold attention, movement, and experience in a number of ways. Dynamic changes in the quality and tempo of tones and rhythm regulates participants' attention, pulls bodily and affective responses out of them, and punctuates the timing and 
quality of both individual movements and patterns of joint music-making that unfold over time. Individuals in this way experience themselves voluntarily "letting go" with the music. However, they also exert some degree of control over this process: Via their own movements, they directly shape the responsive movements and experiences of others. Music can thus serve as scaffolding for the development of selective attention and strengthen individuals' sense of embodied intersubjectivity (Krueger, 2014; Maiese, 2016). While research in this area is still emerging, there is some evidence that improvised sessions creating music with a therapist can lead to at least a short-term reduction in general symptoms (e.g., depression) and negative symptoms in schizophrenic patients (Talwar et al., 2006).

There are also implications for the science of consciousness: While phenomenological approaches have long argued that lived experience is necessarily characterized by a firstperson givenness, known as the minimal self (Zahavi, 2005), this characterization sits uneasily with its deeply social dimension, as revealed by the experiential effects of social disorder in conditions such as schizophrenia (Kyselo, 2016; Ratcliffe, 2017b). Neither does the premise of a minimal self make a good fit with hyperautomaticity: Patients report a complete loss of self, but presumably they continue to experience the flow of consciousness albeit from an apparently egoless vantage point. In such cases, it might be more appropriate to say that there is ongoing experience, but not an experience for or given to "me"; or at least there is significantly weakened sense of ownership (almost, at times, to the point of disappearance) with respect to the experience. Similarly, if first-personal givenness is a necessary component of all experiences, it becomes difficult to accept at face value patients' reports of being confused about the ownership of thoughts and other experiences. Here the structural integration of these experiences into a patient's stream of consciousness evidently remains intact, since they are indeed undergone as lived experiences and can later be recalled, but they seem to lack the quality of first-personal perspectival ownership. 
If so, it would be more parsimonious to agree that all experience is necessarily perspectival; it structurally belongs to a distinct perspective. However, a specifically firstperson perspective from which "I" live through experiences "for me" is an additional achievement that depends on sociocultural capacities (Hutto \& Ilundáin-Agurruza, in press), and these capacities are acquired via social interaction during development (Fuchs, 2013). So, a refinement of the ipseity disturbance model is to say that the distinctive perspectivalness of experience remains intact, but that the additional capacities needed for a stable first-person perspective are disrupted in schizophrenia.

More generally, this turns the science of self-consciousness on its head: Rather than starting with the assumption of self-awareness emerging from a single brain and then trying to overcome the problem of other minds, we start with genuine intersubjectivity emerging from the socially extended mind and then investigate how a stable sense of self can arise from such an ambiguous self-other demarcation.

\section{Acknowledgements}

TF thanks the organizers of the Time, the Body, and the Other conference for the opportunity to test out some of these ideas in front of a lively audience at Heidelberg University.

\section{References}

Alberts, E., Kalverboer, A. F., \& Hopkins, B. (1983). Mother-infant dialogue in the first days of life: An observational study during breast-feeding. Journal of Child Psychology and Psychiatry, 24(1), 145-161.

Bernieri, F. J., \& Rosenthal, R. (1991). Interpersonal coordination: Behavior matching and interactional synchrony. In R. S. Feldman \& B. Rimé (Eds.), Studies in emotion \& 
social interaction. Fundamentals of nonverbal behavior (pp. 401-432). Cambridge, England: Cambridge University Press.

Candadai, M., Setzler, M., Izquierdo, E. J., \& Froese, T. (2019). Embodied dyadic interaction increases complexity of neural dynamics: A minimal agent-based simulation model. Frontiers in Psychology, 10, 1-5. https://doi.org/10.3389/fpsyg.2019.00540

Chartrand, T., \& Bargh, J. A. (1999). The chameleon effect: The perception-behavior link and social interaction. Journal of Personality and Social Psychology, 76(6), 893-910.

Clark, A. (2009). Spreading the joy? Why the machinery of consciousness is (probably) still in the head. Mind, 118(472), 963-993.

de Haan, S., \& Fuchs, T. (2010). The ghost in the machine: Disembodiment in schizophrenia - Two case studies. Psychopathology, 43, 327-333.

De Jaegher, H., \& Di Paolo, E. A. (2007). Participatory sense-making: An enactive approach to social cognition. Phenomenology and the Cognitive Sciences, 6(4), 485-507.

De Jaegher, H., Di Paolo, E. A., \& Gallagher, S. (2010). Can social interaction constitute social cognition? Trends in Cognitive Sciences, 14(10), 441-447.

Di Paolo, E. A., Cuffari, E. C., \& De Jaegher, H. (2018). Linguistic bodies: The continuity between life and language. Cambridge, MA: MIT Press.

Durt, C., Fuchs, T., \& Tewes, C. (Eds.). (2017). Embodiment, enaction, and culture: Investigating the constitution of the shared world, Cambridge, MA: MIT Press.

Froese, T. (2018). Searching for the conditions of genuine intersubjectivity: From agentbased models to perceptual crossing experiments. In A. Newen, L. de Bruin \& S. Gallagher (Eds.), The Oxford handbook of 4e cognition (pp. 163-186). Oxford, England: Oxford University Press.

Froese, T., \& Fuchs, T. (2012). The extended body: A case study in the neurophenomenology of social interaction. Phenomenology and the Cognitive Sciences, 11(2), 205-235. 
Froese, T., Iizuka, H., \& Ikegami, T. (2014). Embodied social interaction constitutes social cognition in pairs of humans: A minimalist virtual reality experiment. Scientific Reports, 4, 1-10. https://doi.org/10.1038/srep03672

Froese, T., Stanghellini, G., \& Bertelli, M. O. (2013). Is it normal to be a principal mindreader? Revising theories of social cognition on the basis of schizophrenia and high functioning autism-spectrum disorders. Research in Developmental Disabilities, 34(5), 1376-1387.

Fuchs, T. (2005). Corporealized and disembodied minds: A phenomenological view of the body in melancholia and schizophrenia. Philosophy, Psychiatry \& Psychology, 12(2), 95-107.

Fuchs, T. (2010). The psychopathology of hyperreflexivity. The Journal of Speculative Philosophy, 24(3), 239-255.

Fuchs, T. (2013). The phenomenology and development of social perspectives. Phenomenology and the Cognitive Sciences, 12(4), 655-683.

Fuchs, T. (2015). Pathologies of intersubjectivity in autism and schizophrenia. Journal of Consciousness Studies, 22(1-2), 191-214.

Fuchs, T. (2018). Ecology of the brain: The phenomenology and biology of the embodied mind. Oxford, England: Oxford University Press.

Fuchs, T., \& De Jaegher, H. (2009). Enacting intersubjectivity: Participatory sense-making and mutual incorporation. Phenomenology and the Cognitive Sciences, 8(4), 465-486.

Fuchs, T., \& Koch, S. C. (2014). Embodied affectivity: On moving and being moved. Frontiers in Psychology, 5, 1-12. https://doi.org/10.3389/fpsyg.2014.00508

Galbusera, L., Finn, M. T., \& Fuchs, T. (2018). Interactional synchrony and negative symptoms: An outcome study of body-oriented psychotherapy for schizophrenia. Psychotherapy Research, 28(3), 457-469. 
Gallagher, S. (2013). The socially extended mind. Cognitive Systems Research, 25-26, 4-12.

Gallotti, M., \& Frith, C. D. (2013). Social cognition in the we-mode. Trends in Cognitive Sciences, 17(4), 160-165.

Gerrans, P., \& McGeer, V. (2003). Theory of mind in autism and schizophrenia: A case of over-optimistic reverse engineering. In B. Repacholi \& V. Slaughter (Eds.), Individual differences in theory of mind: Implications for typical and atypical development (pp. 271-304). New York, NY: Psychology Press.

Goldman, A., \& dee Vignemont, F. (2009). Is social cognition embodied? Trends in Cognitive Sciences, 13(4), 154-159.

Gozé, T., Grohmann, T., Naudin, J., \& Cermolacce, M. (2017). New insight into affectivity in schizophrenia: From the phenomenology of Marc Richir. Psychopathology, 50(6), $401-407$.

Henriksen, M. G., \& Nilsson, L. S. (2017). Intersubjectivity and psychopathology in the schizophrenia spectrum: Complicated we, compensatory strategies, and self-disorders. Psychopathology, 50(5), 321-333.

Herschbach, M. (2012). On the role of social interaction in social cognition: A mechanistic alternative to enactivism. Phenomenology and the Cognitive Sciences, 11(4), 467486.

Hobson, J. A., \& Hobson, R. P. (2007). Identification: The missing link between joint attention and imitation? Development and Psychopathology, 19(2), 411-431.

Hutto, D. D., \& Ilundáin-Agurruza, J. (in press). Selfless activity and experience: Radicalizing minimal self-awareness. Topoi.

Kaye, K. (1982). The mental and social life of babies: How parents create persons. Chicago, IL: The University of Chicago Press. 
Kean, C. (2009). Silencing the self: Schizophrenia as a self-disturbance. Schizophrenia Bulletin, 35(6), 1034-1036.

Kirchhoff, M., \& Kiverstein, J. (2019). Extended consciousness and predictive processing: A third wave view. Abingdon, England: Routledge.

Krueger, J. (2011). Extended cognition and the space of social interaction. Consciousness and Cognition, 20(3), 643-657.

Krueger, J. (2012). Seeing mind in action. Phenomenology and the Cognitive Sciences, 11(2), $149-173$.

Krueger, J. (2013). Ontogenesis of the socially extended mind. Cognitive Systems Research, $25-26,40-46$.

Krueger, J. (2014). Affordances and the musically extended mind. Frontiers in Psychology,

\section{4, 1-13. https://doi.org/10.3389/fpsyg.2013.01003}

Krueger, J. (in press-a). Enactivism, other minds, and mental disorders. Synthese.

Krueger, J. (in press-b). Schizophrenia and the scaffolded self. Topoi.

Krueger, J., \& Aiken, A. T. (2016). Losing social space: Phenomenological disruptions of spatiality and embodiment in Moebius syndrome and schizophrenia. In J. Reynolds \& R. Sebold (Eds.), Phenomenology and Science (pp. 121-139). New York, NY: Palgrave Macmillan.

Krueger, J., \& Henriksen, M. G. (2016). Embodiment and affectivity in Moebius syndrome and schizophrenia: A phenomenological analysis. InJ. A. Simmons \& J. E. Hackett (Eds.), Phenomenology for the twenty-first century (pp. 249-267). London, England: Palgrave Macmillan.

Kupper, Z., Ramseyer, F., Hoffmann, H., \& Tschacher, W. (2015). Nonverbal synchrony in social interactions of patients with schizophrenia indicates socio-communicative deficits. PLoS ONE, 10,1-18. https://doi.org/10.1371/journal.pone.0145882 
Kyselo, M. (2016). The enactive approach and disorders of the self - the case of schizophrenia. Phenomenology and the Cognitive Sciences, 15(4), 591-616.

Lakin, J. L., \& Chartrand, T. L. (2003). Using nonconscious behavioral mimicry to create affiliation and rapport. Psychological Science, 14(4), 334-339.

Lavelle, M., Healey, P. G. T., \& McCabe, R. (2013). Is nonverbal communication disrupted in interactions involving patients with schizophrenia? Schizophrenia Bulletin, 39(5), $1150-1158$.

Lavelle, M., Healey, P. G. T., \& McCabe, R. (2014). Nonverbal behavior during face-to-face social interaction in schizophrenia: A review. The Journal of Nervous and Mental Disease, 202(1), 47-54.

Lysaker, P. H., Johannesen, J. K., \& Lysaker, J. T. (2005). Schizophrenia and the experience of intersubjectivity as threat. Phenomenology and the Cognitive Sciences, 4(3), 335352.

Maiese, M. (2015). Embodied selves and divided minds. New York, NY: Oxford University Press.

Maiese, M. (2016). Affective scaffolds, expressive arts, and cognition. Frontiers in Psychology, 7, 1-11. https://doi.org/10.3389/fpsyg.2016.00359

McGann, M., \& De Jaegher, H. (2009). Self-other contingencies: Enacting social perception. Phenomenology and the Cognitive Sciences, 8(4), 417-437.

Meyer, C., Streeck, J., \& Jordan, J. S. (Eds.). (2017). Intercorporeality: Emerging socialities in interaction. New York, NY: Oxford University Press.

Newen, A., de Bruin, L., \& Gallagher, S. (Eds.). (2018). The Oxford handbook of 4 e cognition. Oxford, England: Oxford University Press.

Parnas, J., \& Handest, P. (2003). Phenomenology of anomalous self-experience in early schizophrenia. Comprehensive Psychiatry, 44(2), 121-134. 
Parnas, J., \& Henriksen, M. G. (2016). Mysticism and schizophrenia: A phenomenological exploration of the structure of consciousness in the schizophrenia spectrum disorders. Consciousness and Cognition, 43, 75-88.

Parnas, J., Møller, P., Kircher, T., Thalbitzer, J., Jansson, L., Handest, P., \& Zahavi, D. (2005). EASE: Examination of Anomalous Self-Experience. Psychopathology, 38(5), $236-258$.

Raffard, S., Salesse, R. N., Bortolon, C., Bardy, B. G., Henriques, J., Marin, L., ... Capdeville, D. (2018). Using mimicry of body movements by a virtual agent to increase synchronization behavior and rapport in individuals with schizophrenia. Scientific Reports, 8, 1-10. https://doi.org/10.1038/s41598-018-35813-6

Ratcliffe, M. (2007). Rethinking commonsense psychology: A critique of folk psychology, theory of mind and simulation. New York, NY: Palgrave Macmillan.

Ratcliffe, M. (2017a). Real hallucinations: Psychiatric illness, intentionality, and the interpersonal world. Cambridge, MA: MIT Press.

Ratcliffe, M. (2017b). Selfhood, schizophrenia, and the interpersonal regulation of experience. In C. Durt, T. Fuchs \& C. Tewes (Eds.), Embodiment, enaction, and culture: Investigating the constitution of the shared world (pp. 149-171). Cambridge, MA: MIT Press.

Sass, L. (2017). Madness and modernism: Insanity in the light of modern art, literature, and thought. Oxford, England: Oxford University Press.

Sass, L., Pienkos, E., Škodlar, B., Stanghellini, G., Fuchs, T., Parnas, J., \& Jones, N. (2017). EAWE: Examination of Anomalous World Experience. Psychopathology, 50(1), 1054.

Sass, L. A., \& Parnas, J. (2003). Schizophrenia, consciousness, and the self. Schizophrenia Bulletin, 29(3), 427-444. 
Schilbach, L., Timmermans, B., Reddy, V., Costall, A., Bente, G., Schlicht, T., \& Vogeley, K. (2013). Toward a second-person neuroscience. Behavioral and Brain Sciences, 36(4), 393-462.

Searle, J. R. (1990). Collective intentions and actions. In P. Cohen, J. Morgan \& M. E. Pollack (Eds.), Intentions in communication (pp. 401-415). Cambridge, MA: MIT Press.

Simonsen, A., Fusaroli, R., Skewes, J. C., Roepstorff, A., Campbell-Meiklejohn, D., Mors, O., \& Bliksted, V. (2019). Enhanced automatic action imitation and intact imitationinhibition in schizophrenia. Schizophrenia Bulletin, 45(1), 87-95.

Slaby, J. (2014). Emotions and the extended mind. In C. von Scheve \& M. Salmela (Eds.), Collective emotions: Perspectives from psychology, philosophy, and sociology (pp. 32-46). Oxford, England: Oxford University Press.

Spurrett, D., \& Cowley, S. J. (2004). How to do things without words: Infants, utteranceactivity and distributed cognition. Language Sciences, 26(5), 443-466.

Srinivasan, S. M., \& Bhat, A. N. (2013). A review of "music and movement" therapies for children with autism: Embodied interventions for multisystem development. Frontiers in Integrative Neuroscience, 7, 1-15. https://doi.org/10.3389/fnint.2013.00022

Stanghellini, G. (2004). Disembodied spirits and deanimated bodies: The psychopathology of common sense. New York, NY: Oxford University Press.

Stanghellini, G., Ballerini, M., \& Mancini, M. (2017). Other persons: On the phenomenology of interpersonal experience in schizophrenia (ancillary article to EAWE Domain 3). Psychopathology, 50(1), 75-82.

Stephensen, H., \& Parnas, J. (2018). What can self-disorders in schizophrenia tell us about the nature of subjectivity? A psychopathological investigation. Phenomenology and the Cognitive Sciences, 17, 629-642. 
Sutton, J. (2008). Between individual and collective memory: Coordination, interaction, distribution. Social Research, 75(1), 23-48.

Sutton, J., Harris, C. B., Keil, P. G., \& Barnier, A. J. (2010). The psychology of memory, extended cognition, and socially distributed remembering. Phenomenology and the Cognitive Sciences, 9(4), 521-560.

Taipale, J. (2016). Self-regulation and beyond: Affect regulation and the infant-caregiver dyad. Frontiers in Psychology, 7, 1-13. https://doi.org/10.3389/fpsyg.2016.00889

Talwar, N., Crawford, M. J., Maratos, A., Nur, U., McDermott, O., \& Procter, S. (2006). Music therapy for in-patients with schizophrenia: Exploratory randomised controlled trial. The British Journal of Psychiatry, 189, 405-409.

Tomasello, M. (1999). The cultural origins of human cognition. Cambridge, MA: Harvard University Press.

Tronick, E. (2005). Why is connection with others so critical? The formation of dyadic states of consciousness and the expansion of individuals' states of consciousness: Coherence governed selection and the co-creation of meaning out of messy meaning making. In J. Nadel \& D. Muir (Eds.), Emotional development: Recent research advances (pp. 293-316). New York, NY: Oxford University Press.

Van Baaren, R. B., Holland, R. W., Kawakami, K., \& Van Knippenberg, A. (2004). Mimicry and prosocial behavior. Psychological Science, 15(1), 71-74.

Van Duppen, Z. (2017). The intersubjective dimension of schizophrenia. Philosophy, Psychiatry \& Psychology, 24(4), 399-418.

Varga, S. (2013). Vulnerability to psychosis, I-thou intersubjectivity and the praecox-feeling. Phenomenology and the Cognitive Sciences, 12(1), 131-143.

Varga, S., \& Krueger, J. (2013). Background emotions, proximity and distributed emotion regulation. Review of Philosophy and Psychology, 4(2), 271-292. 
Wiltermuth, S. S., \& Heath, C. (2009). Synchrony and cooperation. Psychological Science, 20(1), 1-5.

Zahavi, D. (1999). Self-awareness and alterity: A phenomenological investigation. Evanston, IL: Northwestern University Press.

Zahavi, D. (2001). Husserl and transcendental intersubjectivity: A response to the linguisticpragmatic critique. Athens, OH: Ohio University Press.

Zahavi, D. (2005). Subjectivity and selfhood: Investigating the first-person perspective. Cambridge, MA: The MIT Press.

Zahavi, D. (2014). Self and other: Exploring subjectivity, empathy, and shame. Oxford, England: Oxford University Press. 